\title{
Improving Graduate STEM Education through Increased Use of the Case Study Method
}

\author{
Erik A. Zavrel \\ Department of Biomedical Engineering, Cornell University, New York, USA \\ Email: eaz29@cornell.edu
}

Received 31 May 2015; accepted 3 July 2015; published 6 July 2015

Copyright (C) 2015 by author and Scientific Research Publishing Inc.

This work is licensed under the Creative Commons Attribution International License (CC BY). http://creativecommons.org/licenses/by/4.0/

\section{(c) (i) Open Access}

\begin{abstract}
The challenges confronting the United States and the world are increasingly scientific and technological in nature with corresponding solutions rooted in the fields of science, technology, engineering, and mathematics (STEM). Policymakers are increasingly soliciting input and advice from experts in the STEM disciplines. To be successful in a future advisory role requires that current graduate students become more than just authorities in their respective fields. To serve in a capacity to influence national policy and help craft solutions to the world's most pressing challenges requires universities instill other qualities and attributes in their graduate students. This can be accomplished through greater adoption and more frequent use of the case study method. The case study approach to teaching, rarely used in STEM at the undergraduate level and even less frequently utilized at the graduate level, has the potential to help students thrive in graduate school and prepare them to later work with policymakers to address national and global challenges.
\end{abstract}

\section{Keywords}

STEM, Graduate Student Education, International Student Education, Case Study Method, Policymaking

\section{Introduction}

Increasingly, the challenges confronting the United States and the world are scientific and technological in nature with corresponding solutions rooted in the fields of science, technology, engineering, and mathematics (STEM). Problems such as climate change, pollution, natural resource depletion, loss of biodiversity, and access to healthcare are, at their core, STEM issues (Muller, 2008). Quite appropriately then, remediation requires STEM-based solutions. Policymakers are coming to realize that they cannot simply legislate their way to effective 
solutions and are soliciting input and advice from experts in the STEM disciplines (Muller, 2012). To be successful in such a future advisory role requires current graduate students become more than just authorities in their respective fields. Indeed, to serve in a capacity to influence policy at a national level and help craft solutions to the world's most intractable problems requires universities instill other qualities and attributes in their graduate students. Doing so will not just make them more competent academics, but more able to confront pressing national and global challenges. These essential traits include strong communication and interpersonal skills, the ability for independent, impartial critical thinking, and the capacity to consider the context of an issue and be cognizant of relevant historical precedent and parallels. This can be accomplished without a massive allocation of resources and with minimal alteration to the established graduate school paradigm through greater adoption and more frequent use of the case study approach to teaching. The case study method is rarely used in STEM at the undergraduate level and even less frequently utilized at the graduate level, yet has the potential to help students thrive in graduate school and prepare them to later work with legislators to address national and global problems. This treatment examines the unique challenges of STEM education at the graduate level and how the case study method can be used to address these challenges to ensure graduates have the necessary skills to work successfully with policymakers later in their careers.

\section{The Case Study Method}

The case study approach represents a fundamental departure from the traditional lecture-based format of teaching. In the case study approach, one examines a specific example or instantiation of a principle or concept, and from that, a more general and widely applicable understanding can be developed. It is a bottom-up approach employing inductive logic and moving from the specific to the general. It contrasts with traditional teaching where depth is sacrificed for breadth with a top-down approach employing deductive logic and moving from the general to the specific. The case study method mirrors the true nature of graduate research where students are presented with a very specific project with certain objectives, milestones, and deliverables and must become consummate experts on it.

\section{Communication Skills}

Unlike undergraduate education, where a student's success is determined solely by performance on problem sets and exams, success in graduate school is largely dependent on a student's communication abilities and interpersonal skills. In weekly group meetings, graduate students must clearly articulate progress, share obstacles, seek advice, and offer insights to fellow group members. Long-winded deliveries are eschewed for brevity and conciseness. In journal club meetings, group members summarize and share relevant contemporary research findings. Being able to identify the salient aspects of a journal article and communicate them in a manner that is succinct but doesn't oversimplify is a critical skill. Being articulate is essential when attending workshops and conferences. Being able to clearly convey one's motivation, reasoning, and interpretation of results are indispensable when submitting abstracts and communicating findings in a journal article. Communication skills are of paramount importance when applying for grants or submitting progress reports to funding agencies. They are also crucial when vying for post-doctoral or faculty positions upon graduation.

Many graduate students in the STEM disciplines are international. Often, when these students are new to the United States, a language and cultural barrier exists. This barrier adversely affects everyone: the graduate students themselves, their advisers, and the undergraduate students who rely on them as teaching assistants. To address this, international students are frequently required or encouraged to take intensive remedial English courses to improve their communication skills (http://www.sce.cornell.edu/ps/eiss/index.php). These courses are often resented as an additional burden on graduate students already busy with advanced classes, teaching duties, and research. Moreover, after excelling in their demanding undergraduate coursework, international students may be stung by the implication of having to take a remedial course explicitly designed to address deficiencies. This issue is not an ephemeral one as many of these international students will remain in the United States indefinitely and become permanent residents or naturalized citizens. Even domestic graduate students find that after years of taking nothing but STEM courses, their writing and communication skills have withered and atrophied.

The case study approach to teaching can significantly improve the communication and interpersonal skills of international and domestic students alike. Case studies are essentially stories: they incorporate a narrative in their telling (Herreid, 2007). Employing case studies in graduate classes and having students craft their own 
cases can improve their communication skills in a far more natural way than a crash course in language and culture. Also, because cases are incorporated into classes already being taken, students will see them as relevant $r$ ather than as an additional onus upon them.

\section{Critical Thinking}

Success as a graduate student means being able to think critically and independently, impartially weighing evidence and drawing valid conclusions. It means being able to divorce and divest oneself from the issue at hand and avoid personal entanglement. Being a successful graduate student means recognizing that the ultimate truth may be unexpected, counterintuitive, or even contrary to one's desires. It means accepting that designs may require workarounds or compromises and solutions may not always be beautiful or elegant.

The case study approach encourages critical thinking and objectivity (Herreid \& Schiller, 2013). In a typical case study, conflicting claims and pieces of evidence are presented (Herreid, 1997/1998). The motivations of various stakeholders in an issue are explored (Herreid, 2006a). With the interrupted case study, a progressive disclosure method is employed where one must modify inferences and assumptions in light of new information (Herreid, 2006b). This mirrors real world situations where an issue may initially be muddy or unclear with necessary information becoming available only later (Herreid, 2005). All along, policymakers and their advisers must do the best they can with the information at their disposal and have the courage and character to alter-or even reverse- their stance in light of new developments.

\section{Context}

When serving in an advisory capacity, it is essential to be able to provide input with an appropriate context and to recognize relevant historical precedent and parallels (Crichton, 2004). At the interface of science and policy, it is imperative to put the issue at hand into a social context. At the same time, being able to recognize historical precedent and identify historical parallels helps to avoid problems that befell previous science policy legislation. Well-meaning but fundamentally flawed implementation, hubris, and bravado have all contributed to failures of science policy in the past (Crichton, 2002). By providing a narrative and context (Herreid et al., 2012), case studies serve the critical role of having graduate students in the STEM fields consider the science within a wider framework-not a vacuum.

\section{Implementation}

The increased use of the case study method represents a powerful approach to improving graduate STEM education and ensuring that today's graduate students are prepared to address tomorrow's challenges. Realizing this goal does not require a massive infusion of capital nor does it require a drastic overhaul of the existing graduate school paradigm. Rather, a very modest retailoring of existing lesson plans where the traditional lecture format is occasionally supplemented with the case study approach will suffice. Moreover, far from being resented by faculty who may have to tweak their lesson plans, greater use of the case study approach should be embraced as it will in fact save faculty time in the long run. Rather than having to proofread the work of their students for posters, abstracts, and journal articles, faculty members can have their students hone their communication skills through use of the case study method. Large, digital, university-maintained repositories of peer-reviewed case studies, such as the University at Buffalo's National Center for Case Study Teaching in Science (NCCSTS), already exist and their wholesale use, dissemination, and alteration is permitted and encouraged by the curators of these repositories, diminishing the need to create case studies from scratch (Herreid et al., 2014).

\section{Conclusion}

To be able to call upon experts in the STEM disciplines to advise on policy matters, it is imperative to cultivate the necessary traits while they are graduate students. To ensure that graduate students are prepared to serve in future advisory roles, working closely with elected officials to craft well-reasoned, logically-sound legislation requires that they possess strong communication and interpersonal skills, the ability to think critically and independently, and the capacity to put scientific matters into a greater social context, while being aware of historical precedent and parallels. All of these skills can be dramatically improved with minor revision to existing curricula and negligible additional workload to faculty through greater adoption and more frequent use of the case 
study approach to teaching at the STEM graduate level.

\section{References}

Crichton, M. (2002). Prey. New York: HarperCollins.

Crichton, M. (2004). State of Fear. New York: HarperCollins.

Herreid, C. (1997/1998). What Makes a Good Case? Journal of College Science Teaching, 27, 163-165.

Herreid, C. (2005). The Interrupted Case Method. Journal of College Science Teaching, 35, 4-5.

Herreid, C. (2006a). Using Case Studies to Teach Science. In J. Mintzes, \& W. Leonard (Eds.), Handbook of College Science Teaching (pp. 177-184). Arlington, VA: NSTA Press.

Herreid, C. (2006b). “Clicker” Cases: Introducing Case Study Teaching Into Large Classrooms. Journal of College Science Teaching, 36, 43-47.

Herreid, C. (2007). Start With a Story: The Case Study Method of Teaching College Science. Arlington, VA: NSTA Press.

Herreid, C., \& Schiller, N. (2013). Case Studies and the Flipped Classroom. Journal of College Science Teaching, 42, 62-66.

Herreid, C., Schiller, N., \& Herreid, K. (2012). Science Stories: Using Case Studies to Teach Critical Thinking. Arlington, VA: NSTA Press.

Herreid, C., Schiller, N., \& Herreid, K. (2014). Science Stories You Can Count On: 51 Case Studies with Quantitative Reasoning in Biology. Arlington, VA: NSTA Press.

Muller, R. (2008). Physics for Future Presidents. New York: W. W. Norton \& Company.

Muller, R. (2012). Energy for Future Presidents. New York: W. W. Norton \& Company.

http://www.sce.cornell.edu/ps/eiss/index.php 